\title{
The Responsibility of an Environmental Education in the Students of the Major in Agronomy
}

\author{
Ramirez Garcia F, Llorente Aguilera CY* and Quevedo Palau OL \\ Municipal University Center, Cuba
}

*Corresponding author: Dr C Yendry Llorente Aguilera, Professor Assistant, Centro Universitario Municipal, Cuba, Tel: 5354666359; Email: yllorentea@uho.edu.cu

\section{Investigation Paper}

Volume 4 Issue 3

Received Date: March 23, 2020

Published Date: May 13, 2020

DOI: $10.23880 /$ jenr-16000199

\section{Abstract}

Environmental education has been assumed as an alternative in the search of solutions for the conflicts arise between men and nature, in favor of the protection of the environment, and to have influence on the decisions made by governments of the planet to eliminate the causes of global environmental problems.

This work proposes, from our professional profile, to call the attention upon fundamental aspects on the education of new generations on the caring and preservation of the environment in their socio-cultural context. It is aimed to incentivize the responsibility on environmental education during the formation process of students from the major on Agronomy from the Municipal University Center, and its structure answers to the integration of science, technology, and society (STS).

The problem of this investigation was established using theoretical-empirical methods, which allowed establishing the limitation on the knowledge about global, national, and local problems of these students, as its impact on the community. On the other hand, it was demonstrated the limited scenarios of the STS approach and its exploitation.

Keywords: Environmental Education; Environment; Process; Formation; Responsibility; Moral Values

\section{Introduction}

Currently, there is a growing concern about aspects related to Environmental Education and the performance that corresponds to educational institutions in their development. The works of UNESCO, CITMA, and various personalities who, together with the teachers, are in charge of educating on the environment in a responsible and sustainable way have contributed to this [1].

In Higher Education, Environmental Education is assumed by the natural sciences and other disciplines that contribute to a better concrete social historical understanding of environmental phenomena and the impact that their degradation brings to the development of humanity in the natural, economic, social and political environment. The aforementioned education offers enormous potential that can be better exploited through the insertion of the link between school and society.

Now then, Environmental Education is an aspect that, in general sense, has been object of investigation and study from different positions, epistemological, psychological and pedagogical by different specialists from Cuba and other countries, such as by Llorente Aguilera Y [2].

Others like Orestes Valdés [3], whose works are related to Environmental Education in the educational teaching process and Eduardo Torres Consuegra and Oreswte Valdés Valdés [4], address issues related to Environmental Education in the formation of values and ethical behavior. Ismael Santos Abreu [5], with works related to interdisciplinarity in Environmental Education; Rogelio Díaz Castillo [6], with didactic proposals to develop Environmental Education; 


\section{Journal of Ecology and Natural Resources}

Martha Roque Molina [7] with works aimed at environmental training in higher education, are important references for this research; as well as Margarita McPherson Sayú [8], who offers proposals for Environmental Education in teacher training.

In particular, the manifestations observed in the formation of responsibility towards Environmental Education from the direction of the pedagogical process in Higher Education are summarized as follows:

$>$ Limited knowledge of the main global and local problems; its impact on the community, which disadvantages adequate modes of responsible action towards the conservation, improvement, rehabilitation and monitoring of the environment.

$>$ There is little motivation for the care and conservation of the environment, due to the lack of activities that promote the formation of environmental awareness.

$>$ Insufficient preparation that limits the curricular exit of Environmental Education, with emphasis on global and local problems; its impact on the community in favor of transforming modes of action.

$>$ Activities are not always carried out with an environmental approach that favors the production of knowledge, the formation of feelings and attitudes, that ensures community environmental self-management.

$>$ There is a lack of systematicity in the work of Environmental Education with the students, the family and the community, reflected in their way of acting not consciously and responsibly.

$>$ It is insufficient to take advantage of the teachinglearning process, based on class and personal example, as fundamental ways for Environmental Education.

The insufficiencies declared above allow us to declare the following problem: How to favor the development of the responsibility of Environmental Education in the students of the major in Agronomy of the "Municipal University Center"?

The fundamental cause that affects this problem is related to insufficient theoretical-methodological and practical preparation from the pedagogical and scientifictechnical point of view to introduce environmental education in the teaching and learning process.

To solve the problem, the objective is formulated: to develop teaching activities aimed at encouraging responsibility in environmental education, in the students of the Bachelor's degree in Agronomy at the "Municipal University Center". In correspondence with the stated objective, the following is proposed as a research topic: "The responsibility of an environmental education in the students of the major in Agronomy of the "Municipal University Center".
To solve the problem formulated during the investigation, the following methods were used in the different stages. Theoretical were used with the aim of conceptually interpreting the empirical data found, such as: inductiondeduction; analysis-synthesis and the historical-logical, to determine the essential features of the environmental problem and deduce the most relevant elements. Within empiricals, document review and observation were used: the minutes of the department meetings, methodological preparation, and methodological folder with the minutes of the methodological activities carried out, lesson plans, and attendance and evaluation records (results of class controls) were analyzed to obtain information on aspects related with Environmental Education and the teaching of Natural Sciences.

\section{Development}

The word responsibility comes from the Latin term response (to be able to respond, to correspond with another). Responsibility is the fulfillment of the obligations or care when doing or deciding something, or a way of responding that implies the clear knowledge that the results of fulfilling the obligations or not, fall on oneself. Responsibility can be seen as awareness of the consequences of everything we do or fail to do on ourselves or others.

In the field of study or work, for example, the one who is responsible carries out his tasks with diligence, seriousness and prudence because he knows that things must be done well from the beginning to the end and that this is the only way to obtain true teaching and profit from them.

With responsibility, the individual learns to behave so that he can be trusted, since it guarantees compliance with the commitments made and generates trust and tranquility among people. A responsible person reflects seriously before making any decision, thinking about the results and effects that may affect his own life or that of others; is able to feel what others are feeling and understand the needs of others; recognizes mistakes made and is willing to repair them.

All the above is referred to the ethical, moral and social responsibility, the latter has great relevance in a family community, where parents have the duty to be responsible in the formation of their children and in their contribution to society, with the contribution of their own experience of communion and participation.

\section{Theoretical Concepts on Environmental Education}

Environmental Education has been assumed by men as an alternative to promote the necessary development 


\section{Journal of Ecology and Natural Resources}

of cognitive, affective and behavioral indicators that favors the protection of the environment and influences the final decision-making of the planet's governments to eliminate the causes that generate global environmental problems.

Principle 19 of the Stockholm Declaration (1972) states that: "It is essential to carry out educational work on environmental issues, aimed at both young generations and adults, and with due attention paid to the least privileged sector of the population, to broaden the bases of well-informed public opinion and the conduct of individuals, companies and inspired communities in the sense of their responsibility for the protection and improvement of the environment in all its human dimension.

The author shares what is expressed in this statement, because it contains several points of contact with what is aspired and needed in the field of environmental education: to increase the quality of life of men, transform their ways of life, eliminate consumerism wasteful and irrational and promote rational and sustainable use in balance with it.

Environmental Education as such does not constitute a specific subject in Environmental Education, but is inserted through transversal axes through the various subjects, allowing the application of the integrative qualities of human knowledge.

In the development of Environmental Education, the school plays a leading role, since the teacher has the possibility of training the individual, in addition to training in him love, respect, responsibility and interest in the conservation of all the elements that make up the environment. At school and at home this conservationist awareness of the man of tomorrow must be forged.

These previous arguments show the great importance that is given to Environmental and Health Education, constituting this an educational direction of the Department of Natural Sciences.

In Cuba, from the institutional point of view, it has been the responsibility of the Environment Agency (AMA), subordinated to the Ministry of Science, Technology and Environment (CITMA), to execute and participate in the implementation and control of compliance with the environmental policy of the country, whose legal framework is supported by Law No. 81/97 on the Environment and the complementary and implementing regulations of its content. In turn, the National Environmental Strategy (1977) constitutes the programmatic document for the environmental management work that the Agency displays. This strategy includes the main environmental problems of the country (loss of biological diversity, contamination of sea and land water, deterioration of sanitation and environmental conditions in human settlements, soil degradation and deforestation). Each of these problems is inherent to man, has been generated by his action and requires his conscious participation in the mitigation of the damages caused.

Since 1992, with the Rio Summit, our country has become more aware of the waste that has existed throughout our history. An elevation of environmental culture begins. A fundamental objective of Environmental Education is to ensure that individuals and communities understand the complex nature of the natural and man-made environment, resulting from the interaction of its biological, physical, social, economic and cultural aspects, and acquire the knowledge, practical skills to participate responsibly and effectively in the prevention and solution of environmental problems and in the management of the issue of environmental quality.

The definitions addressed by researchers related to Environmental Education are diverse, this concept is not only contextualized in the teaching of Natural Sciences in Higher Education. Torres and Valdés 1996: Environmental Education "is an approach, a dimension, a way of analyzing and interacting with the environment with all its multivariate complexity and richness that go beyond any limit or point of view that seeks to limit its content. Environmental Education "is an educational process, it is an approach to education, it is a dimension, it is a perspective and it is an alternative to education and Pedagogy, which must be developed basically from school, for the social charge that is given to it in the preparation of children, adolescents, youth and adults for life and constitutes a political, economic and social purpose".

In the "National Environmental Strategy Environmental Education "is a complex and dynamic system of ecological, socio-economic and cultural interrelations of society that evolves through the historical process". "The environmental issue is a complex problem, which is why it is necessary to analyze it from its roots, based on its historical background, as well as the current trends in Environmental Education on a global scale. "Environmental Education "is a permanent and contextual educational process, aimed at awakening the need to universalize human ethics and induce individuals to adopt responsible attitudes and behaviors in relation to the environment, which ensure its protection and the improvement of the quality of life of humanity in the present and the future, all of which implies acquiring consciousness and acting".

This cuoted authors focus their analysis on the need to transform, through environmental education, the attitude of man as an active entity, to favor balance with nature and guarantee the protection of the environment. 


\section{Journal of Ecology and Natural Resources}

The author assumes the interpretation made when he exposes: "the theoretical and methodological importance" because:

$>$ It locates the environment in the field of nature-society relations and takes the principle of the material unity of the world by showing the ecological, socio-economic and cultural interrelationships.

$>$ It allows the conception of reality as a global system with different levels of organization of elements, complex and simultaneous processes deeply interrelated in such a way that by influencing some of them they trigger interactions that affect other elements.

$>$ It specifies the breadth of the limits of reality itself, that is, it has a wide and diverse scope.

$>$ On the other hand, it shows the diversity of content of the environment subject to space and time. This eludes foreign responses because each space has a certain level of development and environmental characteristics that give it identity.

$>$ Another novelty is its global (holistic) dynamic and futuristic character ".

It is appreciated that the aforementioned author reaffirms the importance of this dimension and considers the methodological direction of the teaching-learning process of the school as the fundamental thing that ensures its extension to the community based on the role of the teacher to favor the necessary change of attitude towards the environmental protection.

This analysis of the definition of the concept has significant importance in the methodological direction of the teaching-learning process at school because it allows a systemic approach, a holistic treatment, which encompasses nature, society, what is created by man, man himself and social relations and culture.

Article 27 of the Constitution of the Republic of Cuba, which was amended in 1992, legislates environmental education and assigns responsibility to the State for protecting the environment and natural resources of the country. It recognizes its close connection with sustainable economic and social development to make human life more rational and to ensure the survival, well-being and security of current and future generations. This article is implemented through Law 81 on environmental protection. The scientific policy of MINED is defined in the National Environmental Strategy and is contextualized in the improvement of the National Education System as a guiding activity that has an exit in the study plans from the school to the community.

As a conclusion of the analysis of these definitions, the author takes side, considering that it collects the core indicators of environmental education and centers the school as an early reflection of society and is in charge of extending its actions to it, based on the role of the teacher and the leading role of students, in favor of a change of citizen attitude, in relation to the use and protection of the environment.

From the previous theoretical supports and the deepening carried out by the author, it is concluded that environmental education is an unavoidable priority that cannot be postponed to achieve the production of knowledge, motivations and attitudes that influence the decision-making of world governments in favor of a common agreement for the protection of the environment.

\section{Proposal of Activities to Solve the Problem Formulated in the Municipality of Sagua De Tánamo}

The author assumes a synthesis of the aspects that characterize the environmental situation that are manifested in the town of Sagua de Tánamo, prepared by the CITMA office (Ministry of Science, Technology and Environment), in the territory, addressed by Cuenca García G [9]: "the Municipality of Sagua de Tánamo, is located in the northeast of the province of Holguín, bordered on the north by the municipality of Frank País; by the south, with El Salvador of the Guantánamo province; by the east, with Moa; to the west, with the II Front of the Santiago de Cuba province and the Mayarí municipality, it has an area of $702 \mathrm{~km} 2$, of which $545 \mathrm{~km} 2$ correspond to the Sagua river basin. $70 \%$ of the territory corresponds to the Turquino Plan, so most of it is mountainous with conditions for growing coffee and the flat part is made up of fertile soils favorable to agriculture.

There are 34 contaminating sources directly affecting the territory, among which, 29 that are considered to be the most prominent or extremely active: 29 coffee pulping machines, 2 MINAL establishments and the soft drink factory; as well as the extraction of sand and the urban waste system, with emphasis on the terrible situation found on the ditches of the low areas, as mosquito breeding grounds and highly harmful residues for human health accumulate in them. The aforementioned production centers were built without taking environmental protection into account, they dump their waste into the river, directly affecting water quality and biodiversity. The washing of motor vehicles in the river, the bathing of domestic animals and the extraction of sand cause serious pollution that affects the quality of the water consumed by a large part of the population. The municipality is also affected by the deterioration of the soils, by the incidence of salinization that covers space in thirty ground chibalry in the Juan Díaz valley, a situation that causes low production of the banana crop. Other aspects that impoverish quality of the soils are forest fires, which cause 


\section{Journal of Ecology and Natural Resources}

damage to the topsoil.

The coffee pulping machines constitute a center where the wet and cherry coffee is processed until it is completely dry, in many cases the waste contaminates the waters of streams and rivers.

The municipality has an asphalt plant that has a daily production of 250 tons, the raw materials used are: sand, stone dust, gravel that are extracted from the river and the deposits are not replaced, nor are the affected areas reforested.

In addition, there is an increase in logging, pruning, burning and poaching within the protected area by usufructuaries of rustic farms and unscrupulous settlers.

Another element to consider is the impact that the acid rains transported from Moa by the trade winds from the northeast, especially: sulfur trioxide, sulfur dioxide, nitrogen dioxide, among others, have on the environment of Sagua de Tánamo. Contact with the water vapor in the atmosphere forms the acids and falls in the form of rain.

It is the author's opinion that the "Municipal University Center" from town can influence the transformation of the modes of action of students who do not adopt a responsible attitude regarding the protection of the environment, using the novelty provided by the diagnosis, the integration of content, levels of preparation of teachers, students and new ways of doing things from school to the community.

To stimulate responsibility in students, a series of activities are proposed that require adequate preparation from teachers, which can be achieved through a professional exchange, a practical class and an open class, which offer didactic resources, necessary to give curricular output in an integrative way to the contents of Natural Sciences to favor changes of attitude in the subjects who do not assume responsible behavior before the protection of the environment.

An adequate preparation of the subjects is required, from the individual and collective aspects, that ensures the appropriation of knowledge, methods, procedures and creative activities, that stimulates debate and controversy, where the theoretical domain that makes it possible to understand is achieved, where to do, what to do, how to do and why to do.

These activities can be carried out in the scheduled clases in the general schedule, in the meeting class and in the inter-meetings, which contribute developing the habits and methods of practical work in students, by deepening and exercising theoretical environmental aspects oriented or studied in class and the evaluation of the oriented activities.

The author assumes what was stated by Cuenca García Gil [9], which refers: "The activities are done due to:

$>$ Sensitivity to environmental protection.

$>$ The need to strengthen Environmental Education as part of Cuba's current policy.

$>$ The specific situation of the municipality "Sagua de Tánamo" and in particular the area where the "Municipal University Center" is located.

$>$ The increase in climate change and its impact on the locality."

\section{Conclusions}

Environmental Education and its indicators are supported by an updated bibliography of authors from Cuba, Holguin and Sagua de Tánamo [10].

The results of the environmental diagnosis of the Sagua de Tánamo municipality and of the current state of Environmental Education from the Natural Sciences allowed knowing the cognitive, affective and behavioral needs of the students for their transformation.

The educational activities proposed are in correspondence with the indicators of Environmental Education, the didactics from Natural Sciences and the characteristics of the students of this level of education. They are structured taking into account: title, objective, related content, activity content, methodological suggestions and bibliographies.

The implementation of teaching activities shows that they are adequate and viable. They favor the Environmental Education of the students and adjust to the environmental context of the locality.

\section{References}

1. Llorente AY (2016) Stimulation of flexibility as a quality of creative potentialities in pre-university students through the teaching of Mathematics. 2016 (PhD thesis) University of Holguín.

2. Valdés VO (1995) Environmental education in the educational process in the mountains of Cuba. Thesis approved to obtain the scientific degree of Doctor of Pedagogical Sciences. Central Institute of Pedagogical Sciences. Havana: Ministry of Education.

3. Llorente AY (2018) Social development of the agricultural engineer and his environmental influence. Academic 


\section{Journal of Ecology and Natural Resources}

Relevance Magazine. Vol. 4, No. 8. ISSN 2588-1019, pp: 125-140.

4. Torres CE, Valdéz VO (2001) How to achieve environmental education in your students? Havana. Editorial Pueblo and Education.

5. Santos AI (2001) Ranch Program Sheet 11_ Environmental education for sustainable development from the school institution. MINED, Cuba.

6. Díaz CR (2001) Educational prevention in teenagers, in the context of school and family. Thesis in option to the scientific degree of Doctor of Pedagogical Sciences. Higher Pedagogical Institute "José de la Luz y Caballero". Holguin.

7. Roque MM (2003) Educational strategy for the formation of the environmental culture of Cuban professionals of higher level, oriented to sustainable development. Thesis in option to the scientific degree of Doctor of Educational Sciences (unpublished). Havana, Cuba.

8. MPM (2004) Environmental education for the development of knowledge in the Educational Institution. (Thesis in option to the Title of Doctor of Pedagogical Sciences, Holguín, 2004).

9. Cuenca G (2008) Environmental education towards an integrated approach to knowledge in the area of Natural Sciences. Thesis in option to the title of master in Sciences of the Education. ISP "José de la Luz y Caballero". Holguin. Teacher training. Havana: MINED, 1997, 20 pp.

10. González HZG (2006) Environmental education to integrate the contents of the general pre-university training objectives. Santa Clara. (Thesis in option to the Title of Doctor of Pedagogical Sciences). 